International Journal of Physical Modelling in Geotechnics

Volume 12 Issue 4

Internal imaging of saturated granular free-surface flows

Sanvitale and Bowman
International Journal of Physical Modelling in Geotechnics, 2012, 12(4), 129-142 http://dx.doi.org/10.1680/ijpmg.12.00002 Paper 1200002

Received 27/02/2012 Accepted 06/06/2012

Keywords: fabric/structure of soils/granular materials/landslides/model tests

\title{
Internal imaging of saturated granular free-surface flows
}

Nicoletta Sanvitale PhD

Department of Civil, Environmental and Architectural Engineering,

University of Padova, Italy
Elisabeth T. Bowman PhD, CEng, MICE

Department of Civil and Natural Resources Engineering, University of

Canterbury, Christchurch, New Zealand

This paper presents a novel method to investigate the internal behaviour of saturated granular free-surface flows in the context of high-speed movement. Such an approach aims to study the motion of the solids and fluid within the flow in small-scale model flume tests with a view to better understanding debris flows mechanics. Through the employment of a particular solid, liquid and fluorescent dye and the application of an optical technique that relies on precise matching of refractive indices, the arrangement and re-arrangement of the grains within the fluid can be determined by way of planar laser-induced fluorescence. The adopted methodologies, together with the physical and optical properties of the selected fluid and solid phases, are described. The results of a series of experiments performed in a small laboratory flume are presented. The results show the effectiveness of this technique and the reliability of an artificial glass-oil mixture in reproducing the key features of flows composed of natural materials.

Notation
$C_{\mathrm{K}-\mathrm{C}}$
$C_{\mathrm{U}}$
$C_{\mathrm{Z}}$
$D_{10}$
$D_{50}$
$D_{60}$

$D_{90}$

$e$
$k$
$S F$
$S_{0}$
$\gamma$
$\mu$

empirical coefficient

coefficient of uniformity

coefficient of curvature

effective grain size

mean grain size

particle size for which $60 \%$ of the particles are finer

particle size for which $90 \%$ of the particles are finer

void ratio

saturated hydraulic conductivity

shape factor

specific surface

unit weight of the permeant

dynamic viscosity

\section{Introduction}

In nature, granular flows include numerous and complex phenomena that can arise as gentle processes such as sediment transport in rivers and dune formation or as rapid and catastrophic events such as rock avalanches. Among these mass movements, debris flows, high-speed gravity-driven landslides consisting of soil, rock and water (Hungr et al., 2001), represent one of the most hazardous due to their unpredictable nature, high mobility and destructive power (Iverson, 1997; Jakob and Hungr, 2005). Understanding the dynamics of debris flows has become a critical concern to engineers, owing to a worldwide increase in human settlement of mountainous regions.
The dynamics of concentrated particle-fluid systems, such as that of debris flows, involve various momentum exchange processes that operate simultaneously. The relative importance of inertial granular collisions, sliding friction between grains, viscous shear and solid-fluid interaction depends on several factors as particle size distribution, solid concentration and shear rate (Campbell, 1990, 2006; Iverson, 1997; Savage and Jeffrey, 1981). Both experimental observation (e.g., Bagnold, 1954; Savage, 1979) and numerical simulation (e.g., Campbell and Brennen, 1985; Savage and Hutter, 1989) of granular flows have been used to widen the understanding of such a phenomenon. More specifically, debris flows have been described using analytical (Egashira et al., 2001; Iverson and Denlinger, 2001; Iverson et al., 2010; Pitman and Le, 2005; Takahashi, 1991) and numerical models (Denlinger and Iverson, 2001; Pitman et al., 2003) which need to be calibrated and validated against physical models and/or field observations. In situ measurements are hard to achieve owing to the unpredictable occurrence of catastrophic events and the dangers related to field conditions. Therefore, physical model testing, which allows close control over material properties and boundary conditions, is a useful tool to obtain fundamental observations upon which to base physical rules and to validate mechanistic models.

In many experimental studies of saturated granular flow, small- and large-scale flumes have been used as they mimic the shearing conditions in which natural debris flows may develop (Armanini and Gregoretti, 2000; Armanini et al., 2005; Bowman and Sanvitale, 2009; Chau et al., 2000; Egashira et al., 2001; Iverson et al., 2010; Mainali and Rajaratnam, 
International Journal of Physical Modelling in Geotechnics Volume 12 Issue 4
Internal imaging of saturated

granular free-surface flows

Sanvitale and Bowman
1994; Okada and Ochiai, 2008; Papa et al., 2004; Parsons et al., 2001; Rombi et al., 2006; Takahashi, 2007; Tognacca and Minor, 2000; Zhou et al., 2009). In such experiments, it is possible to observe the flow only at its margins, usually the top and sides, owing to their high opacity. Experimental evidence shows that the dynamics of the inner part of the flow can be different from that inferred by the external boundary measurements (Armanini et al., 2005; Schaefer et al., 2010).

In the last few decades several advanced non-invasive methods such as X-ray computed tomography and magnetic resonance imaging (MRI) have been used to view inside, inter alia, highly concentrated granular flows in a rotating drum, vibrated granular beds and hoppers (Baxter et al., 1989; Bonn et al., 2008; Coussot et al., 2003; Michalowski, 1984; Slominski et al., 2007). However, these techniques require expensive apparatus and complex experimental procedures which preclude their routine use. Another approach involves optical methods which relies on the use of transparent materials by a careful refractive index matching (RIM) of the solid and fluid phase. In geotechnical research, a medium made of crushed glass and a refractive index-matched fluid has been used by Allersma (1982) to study the stress distribution in plane strain problems, and by Konagai et al. (1992) for monitoring soil embankment deformation by way of laser tomography. In recent years the development of imaging techniques such as particle image velocimetry (PIV), particle tracking velocimetry and laser induced fluorescence (LIF), that are suited to the investigation of concentrated particle systems, have renewed interest in the RIM technique. This approach has many advantages over MRI and X-ray techniques since it is reasonably economic, versatile and user-friendly. Wiederseiner et al. (2011) has recently presented a detailed review of this technique with details and procedures that can be found in the technical literature.

The current paper presents a novel approach to investigate the internal mechanics of saturated granular flows, in a free surface condition and in a context of high-speed movement, based on a non-intrusive optical technique using 'transparent debris'. This method, combining the refractive index matching of transparent solid and fluid (Budwig, 1994) with a planar laser induced fluorescence (PLIF) technique (Fontenot and Vigil, 2002; Montemagno and Gray, 1995; Stohr et al., 2003) allows observation of the arrangement and re-arrangement of the grains within the fluid and the evolving behaviour of the flow during motion. Here, the adopted methodology together with the physical and optical properties of the selected fluid and solid phases are described. In particular, the suitability of the artificial mixture to mimic the characteristics of natural materials usually used in laboratory debris flow tests (sand and gravel mixed with water) is examined. The results of a first series of experiments performed in a small laboratory flume show the effectiveness of this technique and the ability of the artificial glass-oil mixture to reproduce key features of flows composed of natural materials.

\section{PLIF technique for granular material}

When an assembly of transparent particles is immersed in a transparent fluid having the same refractive index, the solidliquid mixture becomes transparent as the incident light passes straight through their constituents without substantial refractive deviation. The PLIF technique is a non-intrusive optical method that can be used to distinguish the particles from the fluid. This method uses a fluorescent component in the fluid which is excited by a thin laser light sheet with a wavelength tuned to its absorption band. After some time, the order of microseconds, the component de-excites and emits light at a wavelength larger than the excitation wavelength. This light, known as fluorescence, enables the fabric of the particle-fluid system to be observed and recorded in two-dimensional images by an imaging system normal to the fluorescent plane. The specific component excited by the laser light may be either tracer particles or, as for the experiments presented in this paper, a fluorescent dye dissolved in the fluid. This makes the particles within the laser sheet appear dark against a bright background (Figure 1).

A number of different pairings of transparent particles and associated fluids are suitable (Hassan and DominguezOntiveros, 2008), provided they have compatible refractive indices and are reasonably economic and non-hazardous to work with. Particles made from borosilicate glass, Duran ${ }^{\circledR}$, manufactured by Schott, and a hydrocarbon immersion liquid produced by Cargille Laboratories to closely match the refractive index of Duran ${ }^{\circledR}$ were used in the tests described here. Table 1 shows the physical and optical properties of these materials together with those of real granular soil and water for comparison. A neutral and hydrophobic dye, Nile Red, was added to the fluid phase. This dye, manufactured by SigmaAldrich, is strongly fluorescent in non-aqueous phase. As the spectral behaviour of Nile Red depends on the surrounding solvent environment (Dutta et al., 1996), its absorbance and emission spectra in hydrocarbon oil were examined. Both the absorption and emission profiles exhibit their spectral maxima in the wavelength range $500-600 \mathrm{~nm}$ in which the refractive indices of the oil and glass are close, as shown in Figure 2. In principle, the PLIF method requires index matching at both the excitation and emission wavelength. However, this is impossible to achieve fully, so a compromise must be made. Mismatched indices at the absorption wavelength may lead to scattering and distortion of the laser sheet, resulting in excessive background light or illumination of the particles outside of the measurement plane. Conversely, non-matched conditions at the emission wavelength can produce distortion of the captured images. Figure 3 shows the laser plane through an assembly typical of the experiments. Here, an excellent 

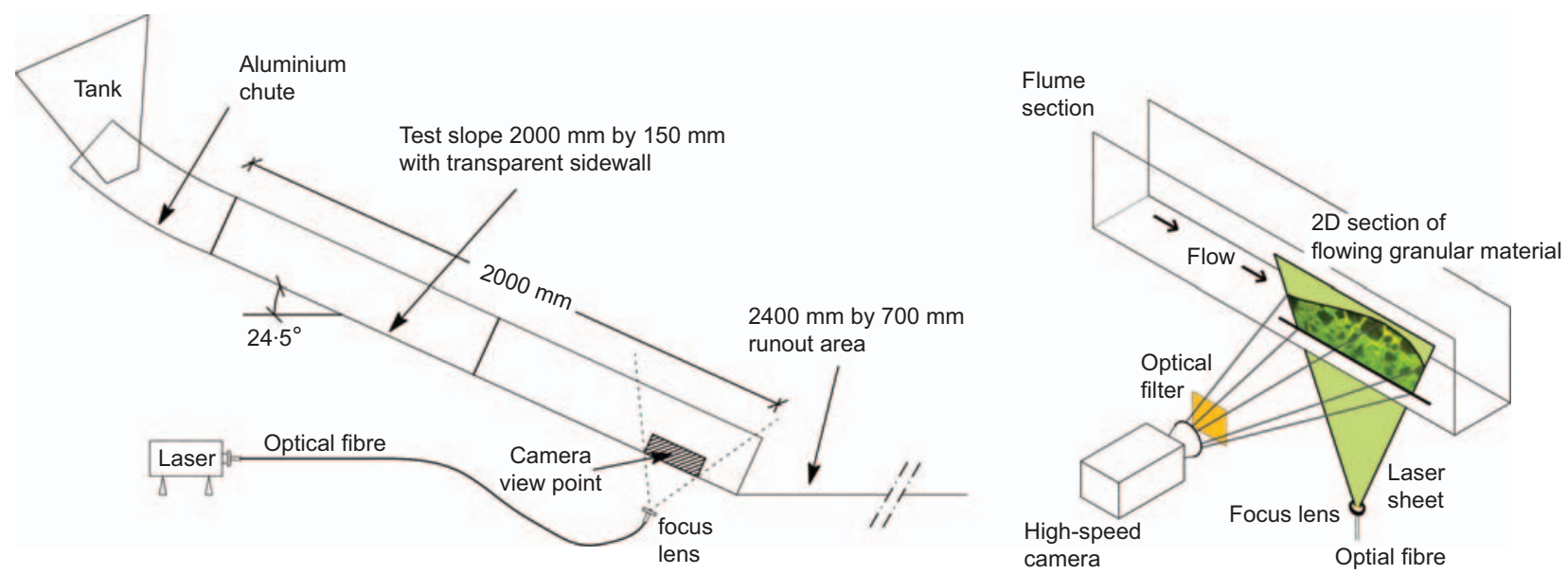

Figure 1. Apparatus employed in the test: (left), arrangement of experimental apparatus; (right), schematic layout of PLIF experimental set-up

match at the emission wavelength was sought, with a reasonable match at the absorption wavelength. As expected, no considerable distortion of the laser plane was detected. The effects of light scattering owing to a slight mismatch at the absorption wavelength were eliminated with the use of a long pass optical filter on the camera lens, resulting in crisp particle images and no areas of excessive brightness. Given the stressoptical coefficient of the borosilicate glass $\left(4 \times 10^{-6} \mathrm{MPa}^{-1}\right)$ and low stresses $(\sim 1 / 2 \mathrm{kPa})$ felt within the medium, little distortion of the refractive index due to stress effects was expected in the experiments.

Although RIM should provide a transparent system, the depth of optical access inside the medium may be reduced by factors such as entrapped air, variations of the refractive index of the liquid caused by temperature sensitivity, imperfections in the solid particles and presence of impurities (Cui and Adrian, 1997; Iskander et al., 2002). A series of simple tests was performed in a glass box to assess the influence of the particle size distribution on the transparency of the mixture. The clarity attainable using a coarse uniform particle size distribution with $C_{\mathrm{U}}=D_{60} / D_{10}=3$ and $D_{50}=11.5 \mathrm{~mm}$ and a well graded one with $C_{\mathrm{U}}=10$ and $D_{50}=7 \cdot 1 \mathrm{~mm}$ were investigated using mixtures with a volumetric solid concentration of 0.57 (i.e. porosity $=0.43$ ) at room temperature around $19^{\circ} \mathrm{C}$. In both cases, the glass particles were deposited inside the box and saturated with the hydrocarbon oil. Before testing, air bubbles were removed by gently stirring the mixture. The images shown in Figure 4 were taken with a high-speed camera set at 200 frames per second (fps) and the laser sheet at two different depths inside the box, $75 \mathrm{~mm}$ and $45 \mathrm{~mm}$. When the coarser particles were used, the transparency of the mixture was high and the single grains could be seen in detail, even at the deepest illuminated section. When the system involved finer particles, the clarity of the images degraded with depth. The presence of smaller particles produces a greater amount of scattered light owing to the slight differences in refractive indices at the grainliquid interfaces. Better optical resolution can be achieved when the laser sheet is placed closer to the outside wall of the container.

\begin{tabular}{lccc}
\hline & Refractive index at $589 \cdot 3 \mathrm{~nm}$ & Density at $25^{\circ} \mathrm{C}: \mathrm{g} / \mathrm{cm}^{3}$ & Kinematic viscosity at $25^{\circ} \mathrm{C}: \mathrm{m}^{2} / \mathrm{s}$ \\
\hline Hydrocarbon oil (Cargille & 1.4715 (at $25^{\circ} \mathrm{C}$ ) & 0.846 & $16 \times 10^{-6}$ \\
$5095)$ & 1.4718 (at $21^{\circ} \mathrm{C}$ ) & 2.23 & - \\
Duran ${ }^{\circledR}$ glass & - & 2.65 & - \\
Soil & 1.3333 (at $20^{\circ} \mathrm{C}$ ) & 1.00 & $(1 \div 10) \times 10^{-6}$ \\
Water in debris flow & & (dependent on clay content)
\end{tabular}


International Journal of Physical Modelling in Geotechnics Volume 12 Issue 4
Internal imaging of saturated granular free-surface flows

Sanvitale and Bowman
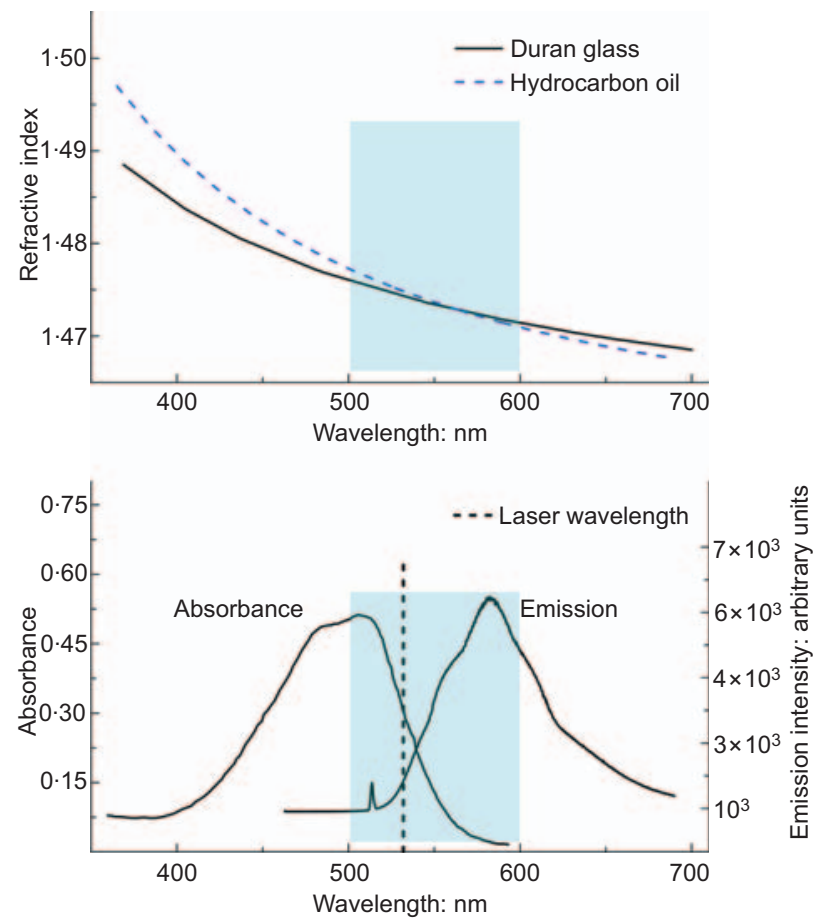

Figure 2. The variation of refractive index against wavelength for Duran glass at $21^{\circ} \mathrm{C}$ (Schott, private communication) and hydrocarbon oil 5095 at $25^{\circ} \mathrm{C}$ (Cargille, private communication) on the top panel. Absorbance and emission spectra of Nile Red in hydrocarbon oil on the bottom panel (the sample concentration is $5 \mathrm{mg} / \mathrm{l})$

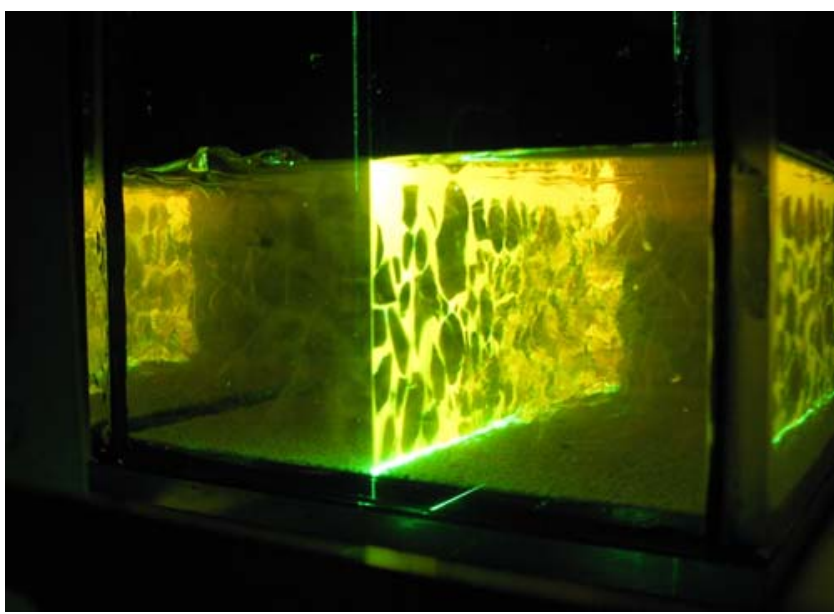

Figure 3. Details of the laser light sheet through the assembly of glass particles immersed in hydrocarbon oil

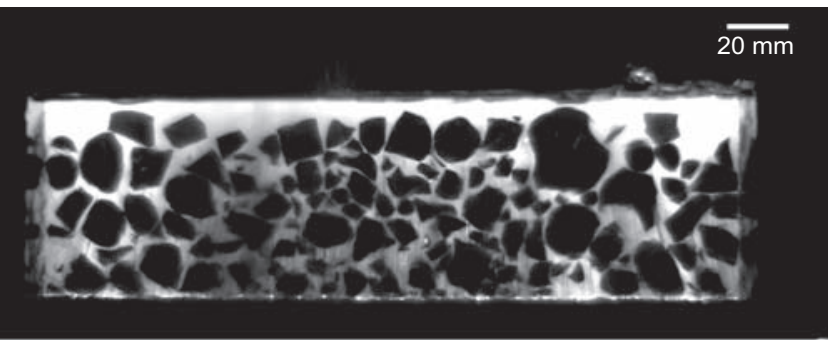

(a)

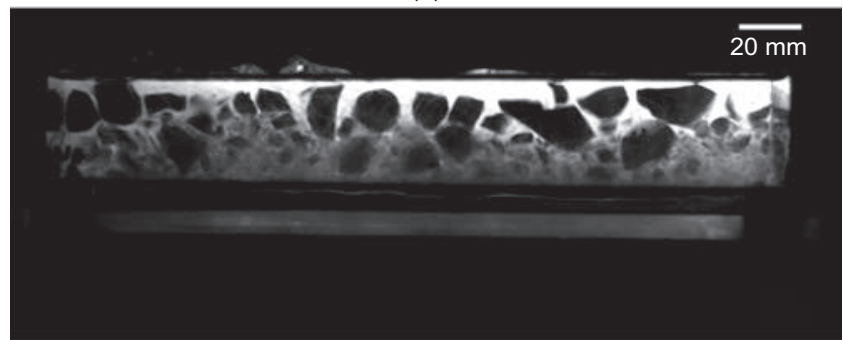

(b)

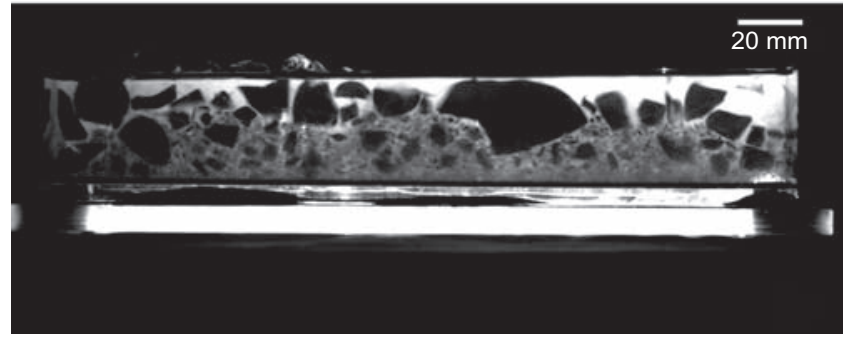

(c)

Figure 4. Camera images of the assembly of glass particles contained in a box. Sections of a uniform (a) and well graded (b) material illuminated by the laser sheet placed $7 \cdot 5 \mathrm{~cm}$ inside the medium. (c) Section of the same well graded material with the laser at $3.5 \mathrm{~cm}$

\section{Experimental set-up}

\subsection{Experimental apparatus}

Figure 1 shows the apparatus used for the experimental debris flows. The main device was a small-scale flume with an aluminium tank at the top of the slope. A curved chute guided the flow from the mouth of the tank to the top of the slope, at which point it travelled down a $150 \mathrm{~mm}$ wide by $2000 \mathrm{~mm}$ long channel before being deposited on a horizontal runout surface. The flume angle could be inclined from $0^{\circ}$ to $40^{\circ}$. The bottom of the channel was made of stainless steel in the upper part and glass in the lower. The glass bottom was artificially roughened over a length of $1 \mathrm{~m}$ with a slip resistant material (3M SafetyWalk $370^{\circledR}$ ) to ensure friction between the bed and the overriding granular flow. The transparent sides were made from poly(methyl methacrylate) except for the lower part, which was made of $1 \mathrm{~m}$ long borosilicate glass sidewalls. A SVSi Memview high-speed camera located near the end of the flume recorded the flow behaviour at a rate of $1100 \mathrm{fps}$ with a 
International Journal of Physical Modelling in Geotechnics Volume 12 Issue 4
Internal imaging of saturated granular free-surface flows Sanvitale and Bowman resolution of $1280 \times 256$ pixels, corresponding to a resolution of approximately $0.2 \mathrm{~mm} / \mathrm{pixel}$ in $x$ and $y$ directions. The 3 gigabyte internal memory of the camera enabled a video recording of 5.9 s. A $50 \mathrm{~mm}$ focal length Navitar DO-5095 lens designed for low light applications was used. During the tests a Schott OG550 long pass filter with the cut-point at 550 $\pm 6 \mathrm{~nm}$, was placed over the lens to transmit only the fluorescence signal. Prior to testing, the granular material was stored in the tank and manually stirred to ensure that the least possible segregation and consolidation took place and to remove any air bubbles before its release. The pneumaticallyoperated trapdoor at the exit point of the tank was linked by a micro switch to the camera to ensure a coordinated time-delay between the release of the material and the recording of the flow. The light source was an $800 \mathrm{~mW}$ solid state laser operating at $532 \mathrm{~nm}$. The laser beam was coupled from the laser head into an optical fibre, recollimated at the fibre output, and then sent through a line generator lens located beneath the flume. The resulting laser sheet, set parallel to the longitudinal direction of the flume, could illuminate the lower part of the channel passing through the bed by means of a slit cut on the rough material stuck on the glass bottom. The slit was $300 \mathrm{~mm}$ long and $1 \cdot 5-2 \mathrm{~mm}$ wide and was placed at a distance of $35 \mathrm{~mm}$ from the transparent sidewall - that is, approximately one quarter of the flume width.

\subsection{Solid properties}

For the purpose of this work, besides being optically compatible, the properties of the adopted solid and fluid were required to compare closely with those of real debris flow materials (Iverson, 1997). The relative densities of the glass and the oil are slightly less than those of soil and water, but the ratio of the densities of the solid and the fluid are the same. Glass particles with irregular shapes were used in order to mimic the friction and rotational resistance between soil grains. Coarse material was produced by cutting cylindrical pieces of glass from rods. These pieces were then shaped to achieve subangular and sub-rounded particles. Finer glass particles were obtained by crushing tubing of different wall thickness. The finer particles turned out to be more angular and elongated than the coarser ones, as shown in Figure 5.

Pore-fluid pressure is crucial to debris flow behaviour because it reduces intergranular friction by way of decreased effective stress and therefore enhances the bulk flow mobility. Pore pressure may be greater than hydrostatic within the flow body to the extent that effective stress reduces to zero and 'liquefaction' occurs (Iverson, 1997). Therefore the development and dissipation of high pore pressure needs careful consideration in physical modelling. As the viscosity of hydrocarbon oil is greater than that of water (see Table 1), to ensure that the drainage behaviour of a typical material adopted in a granular flow laboratory test was maintained,

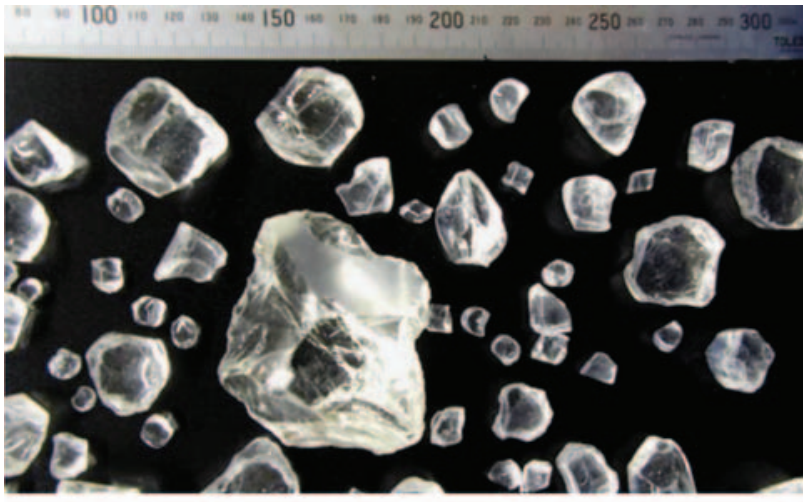

(a)

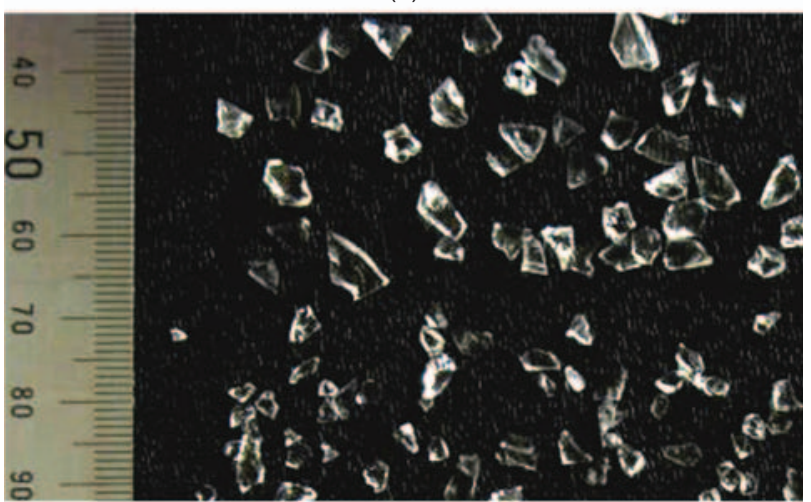

(b)

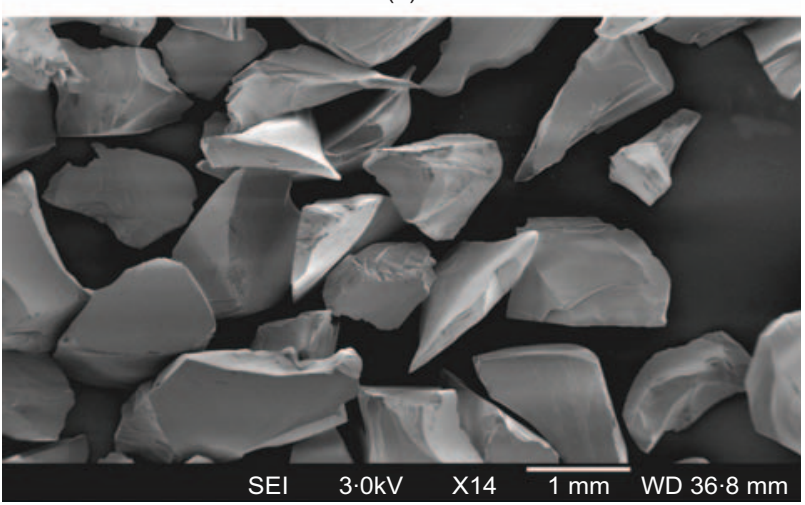

(c)

Figure 5. Glass particles used as transparent solid. Coarse grains (top panel); fine particles smaller than $4 \mathrm{~mm}$ (middle); SEM image of $600 \mu \mathrm{m}$ particles at $14 \times$ magnification (bottom)

particles were scaled up assuming as the prototype a grain size distribution (PSD11) used in previous research on similar chute flow experiments (Bowman and Sanvitale, 2009), as shown in Figure 6.

The Darcy's permeability $k$, more properly referred to as saturated hydraulic conductivity, of any porous material depends on the properties of the permeant, the size of the 
Internal imaging of saturated granular free-surface flows

Sanvitale and Bowman

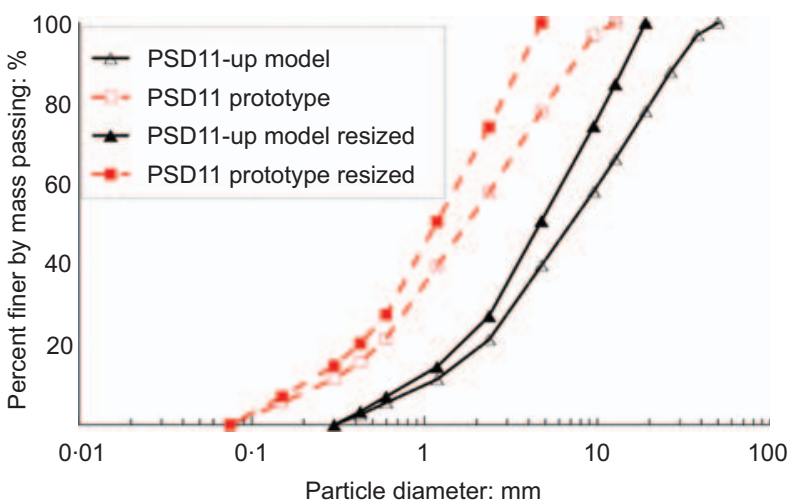

Figure 6. Particle size distributions (PSDs) of the materials used in the permeability tests. The model PSD11-up is larger by a factor 4 in comparison with the prototype PSD11

pores and their geometric characteristics. Many theoretical and empirical relationships (Hazen, 1892; Taylor, 1948; Terzaghi, $1925)$ have been derived that relate $k$ to these properties. Their fundamental formulation may be written as follows (Aubertin et al., 1996)

\section{1. $k=f_{\mathrm{f}} f_{\mathrm{v}} f_{\mathrm{s}}$}

where $f_{\mathrm{f}}, f_{\mathrm{v}}, f_{\mathrm{s}}$ factors take into account the influence of the fluid properties, void space and solid grain surface, respectively. Different expressions for these factors can be adopted, but the most widely used are those proposed in the KozenyCarman equations (Kozeny, 1927; Carman, 1938, 1956) as

2. $f_{\mathrm{f}}=\frac{\gamma_{\mathrm{f}}}{\mu} ; f_{\mathrm{v}}=\frac{e^{3}}{1+e} ; f_{\mathrm{s}}=\frac{1}{C_{\mathrm{K}-\mathrm{C}} S_{0}^{2}}$

where $\gamma$ is the unit weight of the permeant, $\mu$ is the dynamic viscosity of permeant, $e$ is the void ratio, $S_{0}$ is the specific surface and $C_{\mathrm{K}-\mathrm{C}}$ is an empirical coefficient to take into account the pore shape and the tortuosity of the flow path. Specific surface is function of grain size and grain shape (Carrier, 2003; Fair and Hatch, 1933; Loudon, 1952; Sperry and Peirce, 1995), so

3. $f_{\mathrm{s}}=\frac{D_{\mathrm{eff}}^{2}}{C_{\mathrm{K}-\mathrm{C}} S F}$

where $S F$ is a shape factor and $D_{\text {eff }}$ is a representative grain dimension.

For the glass-oil combination, the factor $f_{\mathrm{f}}$ assumes a value that is approximately 18 times smaller than that of a soil-water mixture at $25^{\circ} \mathrm{C}$; hence according to Equation 1, the hydraulic conductivity should vary in the same way. In order to counteract this, the particle size distribution of the glass was scaled up four times, to give an increase in the hydraulic conductivity by 16 times owing to the increase in pore size, represented by $D_{\text {eff. }}$. This assumption holds as long as the fabric of the model medium is comparable with that of the prototype soil, but because of the way the glass particles were produced and the intrinsic properties of glass, the artificial assembly can never be exactly the same as that of a real soil. Compared to the soil grain prototype particles, the glass particles are more smooth and polished, and are very angular and elongated (Figure 7).

In order to verify the effectiveness of particle scaling in controlling the drainage behaviour, the hydraulic conductivity of the artificial (PSD11-up) and the prototype materials (PSD11) were evaluated using two rigid-wall permeameter tests. A large permeameter with an internal diameter of $22.8 \mathrm{~cm}$ was employed for the glass material, while a smaller one, with diameter of $7.6 \mathrm{~cm}$ was used for the soil. The tests were performed according to ASTM D 2434-68 (ASTM, 2000) which requires a permeameter to have a diameter from 8 to 12 times the maximum particle size and any particle larger than $19 \mathrm{~mm}$ to be separated out from the sample by sieving. The particle size distribution resulting from the glass sample without the oversized grains is shown in Figure 6. For the purpose of creating comparable test conditions, the gradation of the soil sample was also modified, removing particles with size larger than $19 / 4=4 \cdot 75 \mathrm{~mm}$. Hydrocarbon oil and water were used as permeants for the glass and soil assembly, respectively. The preparation of the specimens was similar for both the samples. The material was placed in thin layers of 15-20 mm using subsamples prepared according to the target distribution. Before placing the material inside the permeameter, the particles were moistened with a small quantity of fluid in order to prevent size segregation. The permeability tests were performed under constant head with a hydraulic

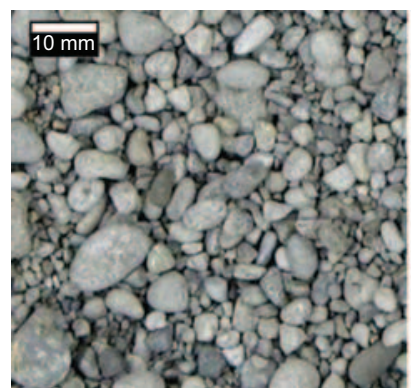

(a)

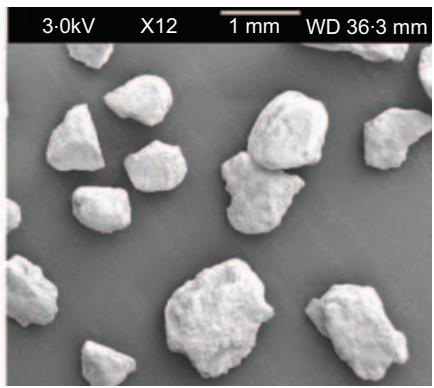

(b)
Figure 7. Soil particles used for the prototype PSD11. Coarse grains (left panel); SEM image of $600 \mu \mathrm{m}$ particles at $12 \times$ magnification (right panel) 
Internal imaging of saturated granular free-surface flows

Sanvitale and Bowman gradient ranging from $0 \cdot 2$ to $0 \cdot 8$ to maintain laminar flow. The results are reported in Table 2 together with the parameters assumed in the calculation of the Kozeny-Carman equation for the particle size distributions. The factors $\gamma, \mu$ and $e$ were known, whereas the terms $D_{\text {eff }}, C_{\mathrm{K}-\mathrm{C}}$ and $S F$ were estimated. $C_{\mathrm{K}-\mathrm{C}}$ is usually taken to be equal to 5 for soils (Carrier, 2003). Assuming the soil consisted of non-uniform spheres, $D_{\text {eff }}$ was calculated from the particle size distribution (Carrier, 2003; Fair and Hatch, 1933; Sperry and Peirce, 1995) according to

4. $\quad D_{\text {eff }}=\frac{100 \%}{\sum\left(f_{i} / D_{\mathrm{ave}_{i}}\right)}$

where $f_{i}$ is the fraction of particles between two sizes ( $D_{1 i}$ and $\left.D_{\mathrm{s} i}\right)$ and $D_{\mathrm{ave}, i}$ is the average particle size between two sieve sizes $\left(=D_{1 i}^{0.5} D_{\mathrm{si}}^{0.5}\right)$. According to Loudon (1952) the shape factor, SF, was estimated to be $7 \cdot 8$ for the soil and 9 for the glass grains by visual inspection of scanning electron microscope images of the particles.

The results confirmed that the hydraulic conductivity of the artificial mixture was similar to that using soil and water and, hence, the adopted particle scaling was appropriate in these terms. Furthermore, the comparison of the predicted and measured values showed the Kozeny-Carman equation to be reliable.

\subsection{Test conditions}

The flume apparatus was used with a slope angle at $24.5^{\circ}$, typical of a debris flow transition reach (Fannin and Wise, 2001), leading to a flat unconfined runout zone. The laser power set at around $600 \mathrm{~mW}$ and the frame rate of the camera at $1100 \mathrm{fps}$. For all of the tests, a mixture was prepared with $12 \mathrm{~kg}$ of glass particles saturated with 3.94 litres of oil for a resulting overall sediment volume concentration $C_{\mathrm{s}}=0.57$ (i.e. porosity $=0 \cdot 43$ ). The concentration of the dye in the oil was $2.5 \mathrm{mg} / \mathrm{l}$. Figure 8 shows the particle size distributions (PSD) of the solid used for the experiments. These grain size curves were created to examine the influence of a change in the coefficient of uniformity $C_{\mathrm{U}}$ at the particular $D_{50}=7 \cdot 1 \mathrm{~mm}$.

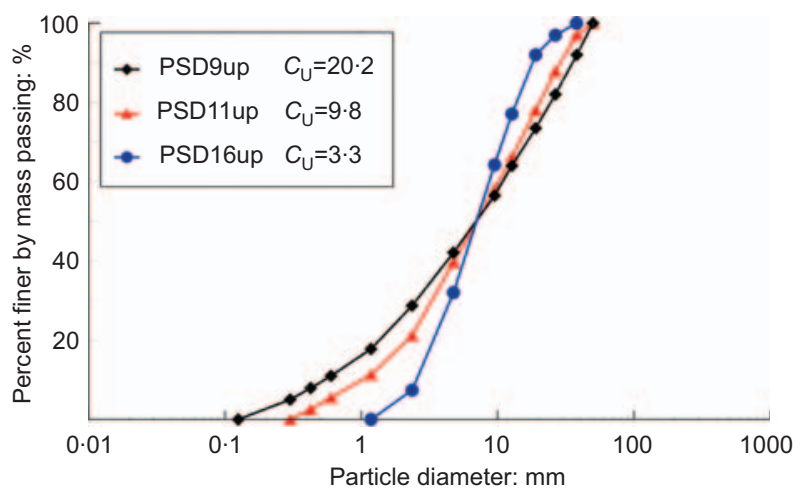

Figure 8. Particle size distributions for the solid materials used in the tests

The grading PSD11up with $C_{\mathrm{U}}=10$ was used for the permeability tests. The gradings PSD9up and PSD16up were chosen in order to have a more well graded $\left(C_{\mathrm{U}}=20 \cdot 2\right)$ and a uniform material $\left(C_{\mathrm{U}}=3 \cdot 3\right)$, respectively, in comparison to PSD11up. For each grading, two experiments were carried out to ensure repeatability of results. Table 3 summarises the main parameters for the tests.

\section{Results}

\subsection{Deposit morphology}

In all of the experiments most of the sediment deposited beyond the flume mouth on the deposition area, though some material was also found on the final part of the channel. Figure 9 shows photographs of the typical runout area for each grading while Figure 10 depicts the deposit fans. Figure 10 shows that the deposit morphology was well reproduced for both experiments of each grading. The coefficient of uniformity has a significant effect on flow mobility, with larger runout observed for larger $C_{\mathrm{U}}$. This behaviour is in agreement with the findings of previous research carried out by Bowman and Sanvitale (2009) using mixtures of soil and water.

\begin{tabular}{|c|c|c|c|c|c|c|c|}
\hline & $D_{\text {eff: }}: m m$ & SF & $\gamma / \mu:(\mathrm{ms})^{-1}$ & $C_{\mathrm{K}-\mathrm{C}}$ & e & k predicted: $\mathrm{m} / \mathrm{s}$ & k measured: m/s \\
\hline PSD11 model resized & $2 \cdot 19$ & 9 & $\begin{array}{l}6 \cdot 13 \times 10^{5}(\mathrm{at} \\
\left.25^{\circ} \mathrm{C}\right)\end{array}$ & 5 & $0 \cdot 62$ & $1.07 \times 10^{-3}$ & $1.42 \times 10^{-3}$ \\
\hline PSD11up prototype resized & $0 \cdot 55$ & $7 \cdot 8$ & $\begin{array}{l}9 \cdot 29 \times 10^{6}(\mathrm{at} \\
\left.18^{\circ} \mathrm{C}\right)\end{array}$ & 5 & 0.58 & $1 \cdot 15 \times 10^{-3}$ & $1.09 \times 10^{-3}$ \\
\hline
\end{tabular}

$D_{\text {eff, }}$ effective diameter; SF, shape factor; $\gamma$, unit weight of the permeant; $\mu$, dynamic viscosity of the permeant; $C_{K-c}$ is an empirical coefficient; $e$, void ratio; $k$, permeability value

Table 2. Adopted parameter values in Kozeny-Carman equation 


\begin{tabular}{|c|c|c|c|c|c|c|c|c|c|}
\hline \multirow[b]{2}{*}{$\begin{array}{l}\text { Particle size } \\
\text { distribution }\end{array}$} & \multicolumn{7}{|c|}{ Initial conditions } & \multicolumn{2}{|c|}{ Results } \\
\hline & $C_{U}$ & $C_{z}$ & $D_{90}: \mathrm{mm}$ & $D_{50}: \mathrm{mm}$ & $D_{10}: \mathrm{mm}$ & $\begin{array}{c}\text { Number of } \\
\text { tests }\end{array}$ & $\begin{array}{c}\text { Volumetric } \\
\text { sediment } \\
\text { concentration }\end{array}$ & Runout: mm & $\begin{array}{c}\text { Front } \\
\text { velocity: } \mathrm{m} / \mathrm{s}\end{array}$ \\
\hline PSD9up & $20 \cdot 2$ & $1 \cdot 1$ & $35 \cdot 5$ & $7 \cdot 1$ & 0.54 & 2 & 0.57 & $\begin{array}{l}94(a) \\
85(b)\end{array}$ & $\begin{array}{l}2 \cdot 48(a) \\
2 \cdot 31(b)\end{array}$ \\
\hline PSD11up & $9 \cdot 8$ & $1 \cdot 1$ & $28 \cdot 7$ & $7 \cdot 1$ & $1 \cdot 1$ & 2 & 0.57 & $\begin{array}{l}70(a) \\
71(b)\end{array}$ & $\begin{array}{l}2 \cdot 04(a) \\
2 \cdot 05(b)\end{array}$ \\
\hline PSD16up & $3 \cdot 3$ & 0.9 & $17 \cdot 6$ & $7 \cdot 1$ & $2 \cdot 7$ & 2 & 0.57 & $\begin{array}{l}60(a) \\
60(b)\end{array}$ & $\begin{array}{l}1 \cdot 49(\mathrm{a}) \\
1.52(\mathrm{~b})\end{array}$ \\
\hline
\end{tabular}

$D_{10}$ and $D_{50}$, effective and mean grain size; $D_{90}$, particle size for which $90 \%$ of the particles are finer; $C_{z}$ coefficient of curvature; $C_{\mathrm{U}}$, coefficient of uniformity

Table 3. Experimental conditions and results

The PSD9up experiments exhibited the longest and thinnest deposits. Their thickness was usually less than $20 \mathrm{~mm}$, except where the biggest particles deposited. The large difference in the slope of the flume and the flat runout area led to an accumulation of sediment close to the exit of the flume, where the thickness of the deposit was greatest ( $30 \mathrm{~mm}$ on average). Some material deposited also along the final part of the flume in correspondence to the roughened bed: that is, approximately $1.0 \mathrm{~m}$ before the mouth of the channel.

The runout for the tests with PSD11up was shorter and slightly wider than for PSD9up. Again, some minor material deposited in the flume but the deposition started further down, around $0.5 \mathrm{~m}$ before the flume exit. The deposit was thicker: in general less than $30 \mathrm{~mm}$, but with a depth around $40-45 \mathrm{~mm}$ close to the exit point.

Deposits formed by PSD16up were the shortest. They had a circular shape and thickness greater than those of PSD11up, approximately $35 \mathrm{~mm}$. The deposition started $0.3 \mathrm{~m}$ before the end of the flume, but in comparison to the other tests, the layers of sediments found in the flume were thinner. In this case, the accumulation of the material at the flume exit was not present. The thickness of the deposit was larger in the centre of the fan and decreased progressively towards the margins.

Sediment samples at the front margin (edge sample) and at the centre (centre sample) of the deposit on the runout area and in the distal part of the channel (flume sample) were collected after each test to examine the gradation of the material (Figure 11). Segregation of particles was more pronounced for the well-graded mixtures. PSD9up and PSD11up presented morphologic features resembling those of natural and laboratory debris flow fans (Major, 1997) with coarse particles accumulating at the front and at the margins of the deposit and fines at the rear.

\subsection{Flow features}

The internal flow dynamics over the illuminated laser section was recorded by the high-speed camera. Figure 12, Figure 13 and Figure 14 show sequences of images for one test of each grading. The flow proceeds from right to left and the camera is tilted at $24.5^{\circ}$ so that in the image the flow appears to be horizontal. In the figures, the parts of the flow from (a) to (d) correspond to (a) the arrival of the flow front; (b) immediately after the front; (c) the core of the flow; (d) the tail of the surge. The thickness of the flows immediately after the front (Figure 15) was estimated from the images. In all of the tests, the arrival of the front was preceded by a few tumbling grains; however, as $C_{\mathrm{U}}$ increased, faster and thinner flows were observed.

The flow behaviour in the runs using the most well graded material (PSD9up) behaved in a similar manner. Figure 12 shows images of the experiment PSD9up-b. The flow was thin and elongated, so that the front and the body had approximately the same height, around $20-30 \mathrm{~mm}$. The thickness at the tail was around $10 \mathrm{~mm}$. The flow segregated during motion with most of the coarse particles concentrating towards the front. Note that, at the front, the material was not saturated and individual particles are visible as illuminated blocks and not as dark spots since the PLIF technique needs full saturation to be effective. This reflects observations of an unsaturated front found in instrumented large-scale flumes and debris flow torrent channels (Iverson, 1997; McArdell et al., 2007). Segregation along the depth was not evident owing to the small thickness of the flow. Nevertheless, a tendency of the coarse particles to position close to the free surface (the line of 
International Journal of Physical Modelling in Geotechnics Volume 12 Issue 4
Internal imaging of saturated granular free-surface flows

Sanvitale and Bowman

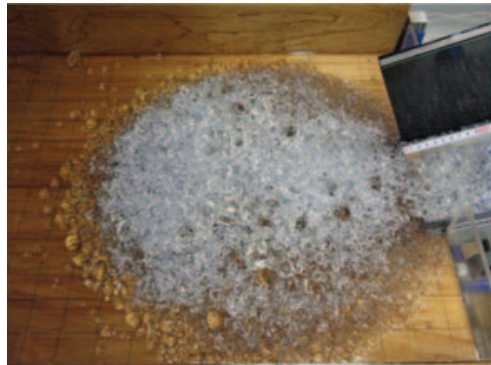

(a)

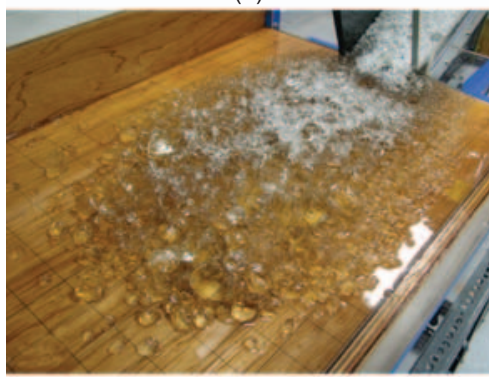

(b)

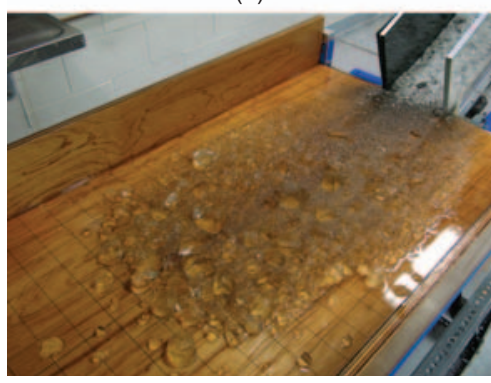

(c)

Figure 9. Photographs of test deposition on the runout area: (a) PSD16up with $C_{U}=3 \cdot 3$; (b) PSD11up with $C_{U}=9 \cdot 8$; (c) PSD9up with $C_{U}=20 \cdot 2$

saturation can be seen as a wavy black line) is notable, with coarse grains appearing to float, which has often been observed in field situations (McArdell et al., 2007; Pierson, 1980), see Figure 12(b) and (c). Particles sufficiently large to be distinguished within the flow exhibited frequent collisions between

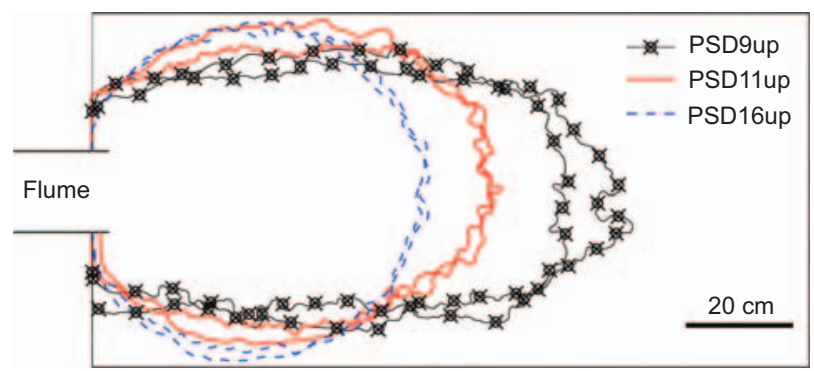

Figure 10. The deposit fans of the performed tests

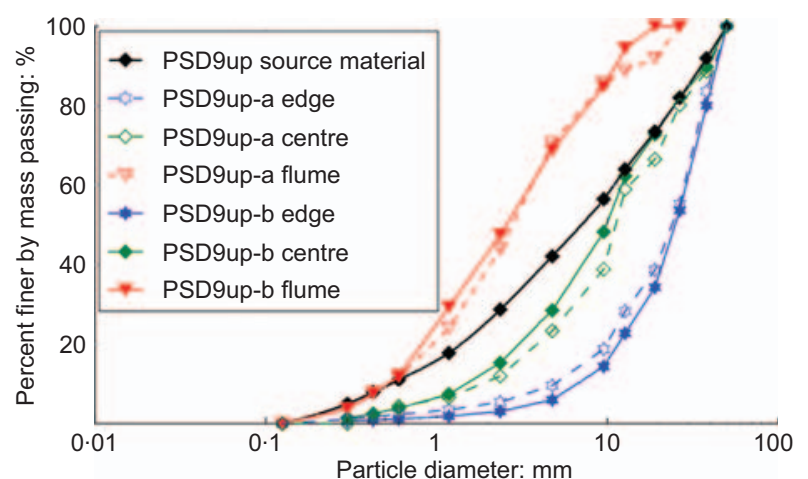

(a)

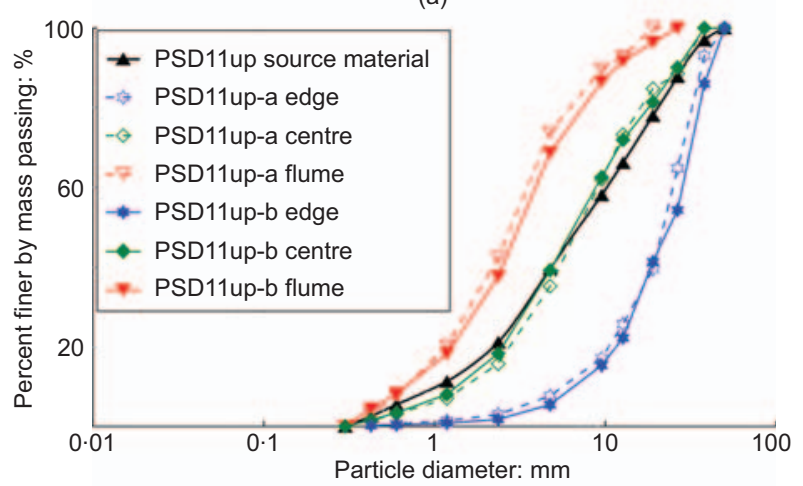

(b)

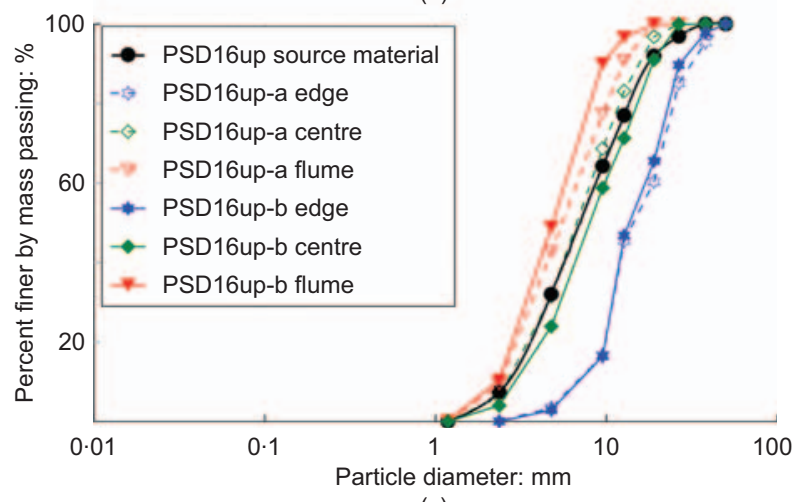

(c)

Figure 11. Particle size distributions of the samples collected at the front and at the centre of the deposit on the runout zone and at the distal part of the channel

each other and the bottom of the channel. The resulting impacts were so strong that the upwards movement after these collisions sometimes made the particles bounce outside the free surface as shown in Figure 16.

Similar behaviour was exhibited by the granular flows using PSD11up. In Figure 13, images of test PSD11up-a are shown. The thickness of the flow was larger than that of PSD9up-b with the front and body $25-40 \mathrm{~mm}$ thick, while the tail was around $10-15 \mathrm{~mm}$ thick. Again individual particles are visible 
International Journal of Physical Modelling in Geotechnics Volume 12 Issue 4
Internal imaging of saturated granular free-surface flows

Sanvitale and Bowman

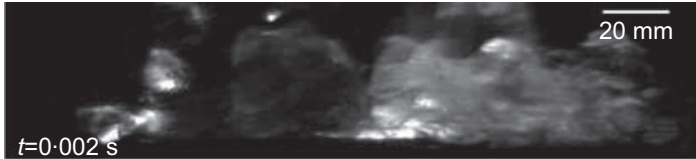

(a)

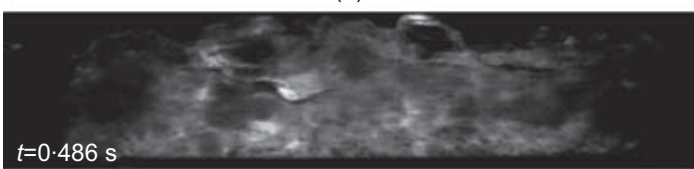

(b)

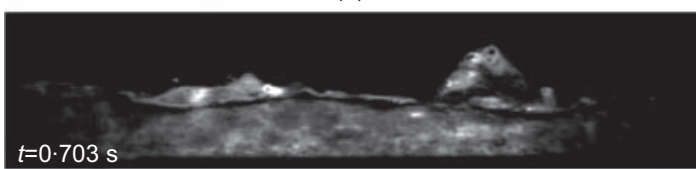

(c)

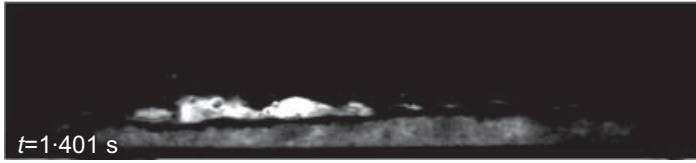

(d)

Figure 12. Digital images of the test using PSD9up-b. The flow is proceeding from right to left: (a) during arrival of the flow front; (b) in the core of the flow; (c) in the tail of the flow; (d) at the end of the flow

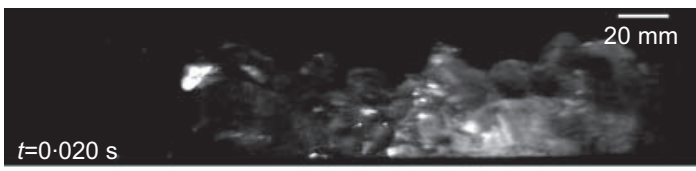

(a)

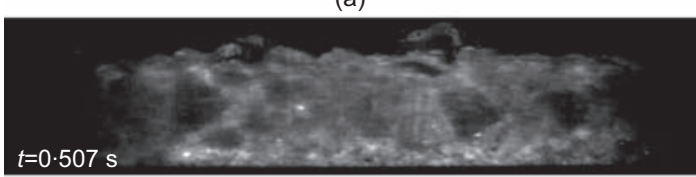

(b)

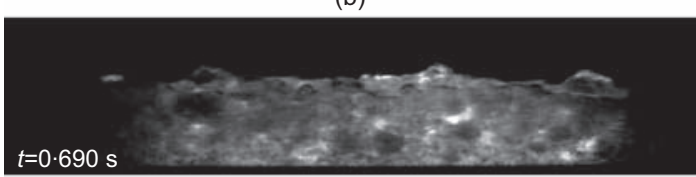

(c)

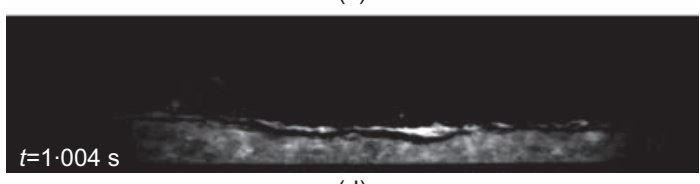

(d)

Figure 13. Digital images of the test using PSD11up-a. The flow is proceeding from right to left: (a) during arrival of the flow front;

(b) in the core of the flow; (c) in the tail of the flow; (d) at the end of the flow

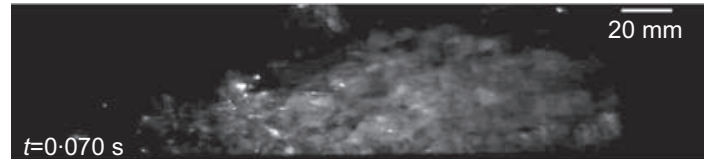

(a)

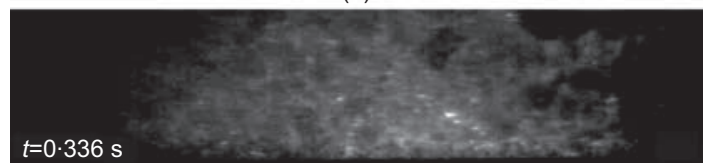

(b)

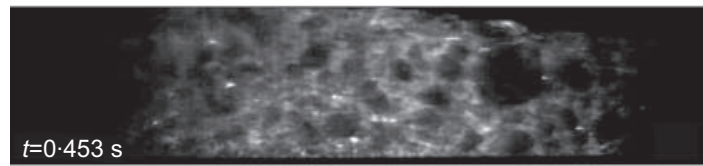

(c)

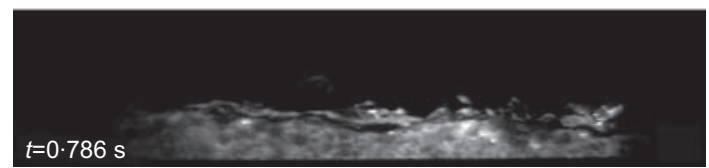

(d)

Figure 14. Digital images of the test using PSD16up-a. The flow is proceeding from right to left: (a) during arrival of the flow front; (b) in the core of the flow; (c) in the tail of the flow; (d) at the end of the flow

as illuminated grains in the unsaturated front. Segregation was evident along the length and the depth of the flow, with the coarser particles concentrated towards the head of the surge and dispersed close to the free surface, as shown in Figure 13(b) and (c). Interaction between the grains was evident, but the collisions were fewer and not so strong in comparison to those of PSD9up. The fluctuation movements were restricted to a small area around the grain (Figure 17).

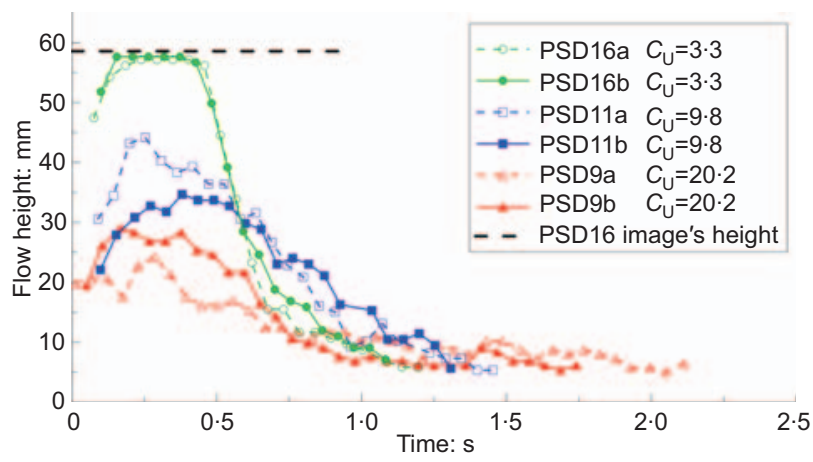

Figure 15. Time evolution of the flow height (note the truncation of flow height for PSD16 tests owing to the thickness of the flow larger than the image's height) 
International Journal of Physical Modelling in Geotechnics Volume 12 Issue 4
Internal imaging of saturated granular free-surface flows

Sanvitale and Bowman

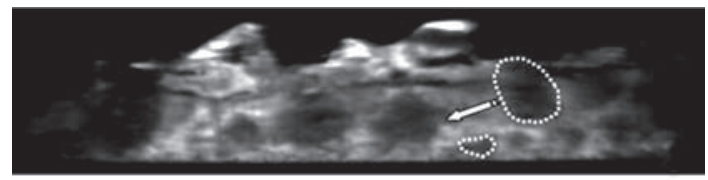

(a)

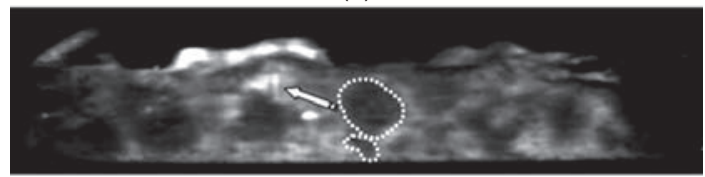

(b)

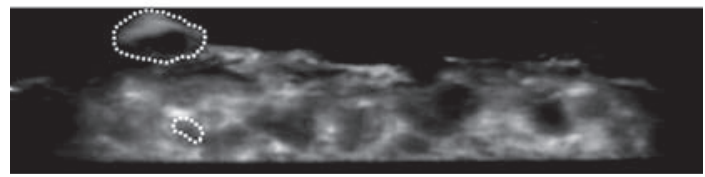

(c)

Figure 16. Strong grain collision during the test PSD9up-a: (a) before the impact; (b) grain interaction; (c) after the collision

Rather different behaviour was exhibited by the tests using the uniform particle size distribution PSD16up, Figure 14. The flow was very thick with a steep front and a bulky body of over $55 \mathrm{~mm}$. A sudden drop in the height of the flow followed, leading to a tail of around $10 \mathrm{~mm}$ thick. In Figure 14(b) and (c), the top of the flow is not visible since the thickness was greater than the image field of view (note the slight truncation above $56 \mathrm{~mm}$ in Figure 15). In Figure 14(a) and (b) the quality of the images is not ideal owing to the presence of air bubbles entrapped inside the flow. Moreover, the large thickness and the high concentration of solid particles partially prevented the penetration of the laser sheet through the mixture. By visual inspection of successive images it appears that the grains immediately after the front moved mostly by sliding over one

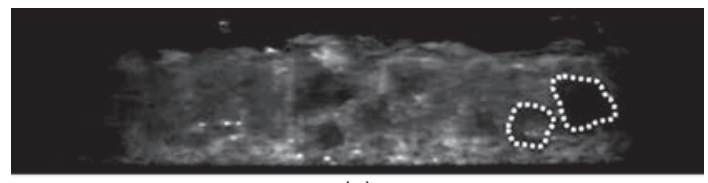

(a)

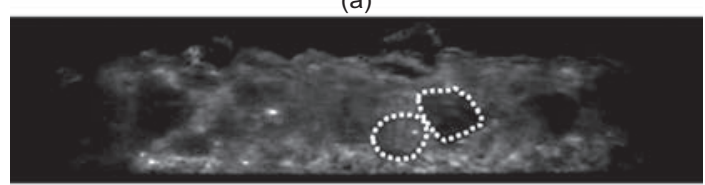

(b)

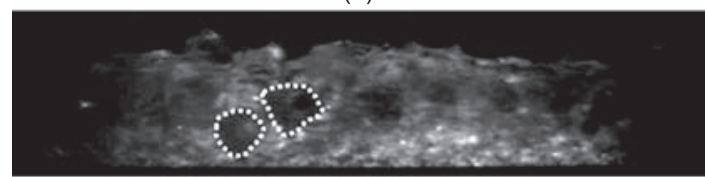

(c)

Figure 17. Grain collision during the test PSD11up-b: (a) before the impact; (b) grain interaction; (c) after the collision another with prolonged frictional contacts. These gradually diminished as the flow evolved and the concentration of the particles decreased as shown in Figure 14(c). From here, the quality of the images improved significantly. The grains in the core and in the tail of the flow presented a few weak collisions that were mostly attributable to direct interactions with the bottom of the channel. Particles appeared homogenously distributed, with no particular segregation evident except for the coarsest particles which accumulated at the front.

These preliminary results provide direct visual evidence of how larger particles in well-graded flows 'focus' towards the front (Suwa, 1988) as they are shunted upwards into faster moving layers (Sanvitale et al., 2011) by way of more violent inertial grain collisions, in comparison to smaller particles. The more well-graded a flow, the more segregation can occur, resulting in a more fluidised finer tail. The fluidised tail aids the mobility of the flow on shallower and less confined reaches where it pushes the decelerating frictional front forwards, leading to greater runout overall and the observed elongated and segregated deposit.

\section{Conclusions}

This paper presents the results of a novel method adopted to analyse the inner behaviour of transparent dense granular flows in a 'free surface' condition and characterised by relatively high-speed movements. The approach aims to study the motion of the solids and fluid within the flow in small-scale flume tests with a view to understanding debris flows mechanics. The method is based on refractive index matching of a transparent solid and fluid to make the system transparent, and the use of PLIF to distinguish the solid particles within the fluid. Among the different pairings suitable for this approach, a mixture of borosilicate glass particles and hydrocarbon oil was adopted. Glass particles were shaped in order to resemble those of real soil grains. As the viscosity of hydrocarbon oil is greater than that of water, to ensure that the drainage behaviour typical of materials used in debris flow laboratory tests was maintained, particles were scaled up. Permeability tests were carried out on both the up-scaled and prototype mixtures to verify the appropriateness of such scaling.

A series of experiments was undertaken in a laboratory chute to investigate the effectiveness of this technique and the reliability of the artificial glass-oil mixture in reproducing the key features of debris flows composed of natural materials. Two-dimensional images of vertical sections through the granular flow were captured by a high-speed camera located near the end of the channel. Three different particle size distributions were used: two well-graded and one uniform. The mobility of the tests in terms of runout exhibited behaviour compatible with that observed in similar flume experiments 
International Journal of Physical Modelling in Geotechnics Volume 12 Issue 4
Internal imaging of saturated granular free-surface flows

Sanvitale and Bowman using natural mixtures (Bowman and Sanvitale, 2009). The morphologic features of the deposit resembled those typical of debris flow fans, particularly those that used the most wellgraded materials. Segregation of the solid particles occurred during the flow and could be observed in images of the tests. The segregation mechanism appeared to chiefly involve inertial particle collisions which were more violent the more wellgraded the material and larger the individual particles involved - a process that may result in a more fluidised tail, dominated by finer material and higher mobility.

These results show that the proposed technique is a valuable tool with which insight may be gained into the mechanics of granular-fluid flows. This method proved to be a reasonably economic, versatile and user friendly approach to acquire internal images inside highly concentrated particle-fluid systems. The main drawback of this method was found to be the time-consuming procedure to produce glass particles with irregular shape resembling those of sand and gravel grains. As an extension of the work shown here, the images recorded during the tests are being used to investigate the internal kinematics using a particle image velocimetry approach Preliminary results are presented in Sanvitale et al. (2011). A more detailed analysis will be given in a coming paper along with a detailed discussion of scaling laws and comparison to typical flow regimes exhibited by large and small debris flows.

\section{Acknowledgements}

The research presented in this paper was supported through the Royal Society of New Zealand under the Marsden Fund grant: 'Investigation of the internal mechanics of debris flows'. The authors would like to thank Professor R. Genevois (University of Padova) for his support of the research activity. Thanks also go to the laboratory staff Messers John Kooloos, Rob MacGregor, Kevin Wines, Peter McGuigan, Ian Sheppard and Siale Faitotonu of the University of Canterbury for help in construction of the flume apparatus and experimental testing.

\section{REFERENCES}

Allersma HGB (1982) Determination of the stress distribution in assemblies of photoelastic particles. Theoretical and experimental description of the application of the photoelasticity method to three-dimensional assemblies of glass particles. Experimental Mechanics 22(9): 336-341.

Armanini A and Gregoretti C (2000) Triggering of debris-flow by overland flow: A comparison between theoretical and experimental results. In Proceedings of the 2nd International Conference on Debris-flow Hazards Mitigation: Mechanics, Prediction and Assessment (Wieczorek G and Naeser ND (eds)). Balkema, Rotterdam, the Netherlands, pp. 117-124. Armanini A, Capart H, Fraccarollo L and Larcher M (2005) Rheological stratification in experimental free-surface flows of granular-liquid mixtures. Journal of Fluid Mechanics 532: 269-319.

ASTM (2000) D 2434-68: Standard Test Method for Permeability of Granular Soils (Constant Head). ASTM International, West Conshohocken, PA, USA.

Aubertin M, Bussière B and Chapuis RP (1996) Hydraulic conductivity of homogenized tailings from hard rock mines. Canadian Geotechnical Journal 33(3): 470-482.

Bagnold RA (1954) Experiments on a gravity-free dispersion of large solid spheres in a Newtonian fluid under shear. Proceedings of the Royal Society of London. Series A. Mathematical and Physical Sciences 225(1160): 49-63.

Baxter GW, Behringer RP, Fagert T and Johnson GA (1989) Pattern formation in flowing sand. Physical Review Letters 62(24): 2825-2829.

Bonn D, Rodts S, Groenink M, Rafai S, Shahidzadeh-Bonn N and Coussot P (2008) Some applications of magnetic resonance imaging in fluid mechanics: complex flows and complex fluids. Annual Review of Fluid Mechanics 40: 209-233.

Bowman ET and Sanvitale N (2009) The role of particle size in the flow behaviour of saturated granular materials. In Proceedings of the 17th International Conference on Soil Mechanics and Geotechnical Engineering (Hamza M, Shahein M and El-Mossallamy Y (eds)). IOS Press, Amsterdam, the Netherlands, pp. 470-473.

Budwig R (1994) Refractive index matching for liquid flow investigations. Experiments in Fluids 17(5): 350-355.

Campbell CS (1990) Rapid granular flows. Annual Review of Fluid Mechanics 22(1): 57-90.

Campbell CS (2006) Granular material flows - an overview. Powder Technology 162(3): 208-229.

Campbell CS and Brennen CE (1985) Chute flows of granular material: some computer simulations. Journal of Applied Mechanics 52(1): 172-178.

Carman PC (1938) The determination of the specific surface of powders. Journal of Society of Chemical Industries Transactions 57: 225-234.

Carman PC (1956) Flow of Gases through Porous Media. Butterworths, London, UK.

Carrier DW (2003) Goodbye, Hazen; Hello, Kozeny-Carman. Journal of Geotechnical and Geoenvironmental Engineering 129(11): 1054-1056.

Chau KT, Chan LCP, Luk ST and Wai WH (2000) Shape of deposition fan and runout distance of debris-flow: Effects of granular and water contents. In Proceedings of the 2 nd International Conference on Debris-flow Hazards Mitigation: Mechanics, Prediction and Assessment (Wieczorek G and Naeser ND (eds)). Balkema, Rotterdam, the Netherlands, pp. 387-395.

Coussot P, Raynaud J and Ancey C (2003) Combined MRIrheometry determination of the behavior of mud suspensions. In Proceedings of the 3rd International Conference on Debris-flow Hazards Mitigation: Mechanics, 
International Journal of Physical Modelling in Geotechnics Volume 12 Issue 4
Internal imaging of saturated granular free-surface flows

Sanvitale and Bowman
Prediction and Assessment (Rickenmann D and Chen C (eds)). Millpress, Davos, Switzerland, pp. 291-301.

Cui MM and Adrian RJ (1997) Refractive index matching and marking methods for highly concentrated solid-liquid flows. Experiments in Fluids 22(3): 261-264.

Denlinger RP and Iverson RM (2001) Flow of variably fluidised granular masses across three-dimensional terrain. 2 . Numerical predictions and experimental tests. Journal of Geophysics Research 106(B1): 552-566.

Dutta AK, Kamada K and Ohta K (1996) Spectroscopic studies of Nile red in organic solvents and polymers. Journal of Photochemistry and Photobiology 93(1): 57-64.

Egashira S, Honda N and Itoh T (2001) Experimental study on the entrainment of bed material into debris flow. Physics and Chemistry of the Earth, Part C: Solar, Terrestrial, and Planetary Science 26(9): 645-650.

Fannin RJ and Wise MPW (2001) An empirical-statistical model for debris flow travel distance. Canadian Geotechnical Journal 38(5): 982-994.

Fair GM and Hatch LP (1933) Fundamental factors governing the streamline flow of water through sand. Journal of the American Water Works Association 25(11): 1551-1565.

Fontenot MM and Vigil RD (2002) Pore-scale study of nonaqueous dissolution in porous media using laserinduced fluorescence. Journal of Colloid and Interface Science 247(2): 481-489.

Hassan YA and Dominguez-Ontiveros EE (2008) Flow visualization in a pebble bed reactor experiment using PIV and refractive index matching techniques. Nuclear Engineering and Design 238(11): 3080-3085.

Hazen A (1892) Some physical properties of sands and gravels, with special reference to their use in filtration. In 24th Annual Report of the Massachusetts State Board of Health. State Board of Health, Boston, MA, USA, Pub. Doc. No. 34, pp. 539-556.

Hungr O, Evans SG, Bovis M and Hutchinson JN (2001) Review of the classification of landslides of the flow type.

Environmental and Engineering Geoscience VII(3): 221-238.

Iskander M, Sadek S and Liu J (2002) Optical measurement of deformation using transparent silica gel to model sand. International Journal of Physical Modelling in Geotechnics 2(4): 13-26.

Iverson RM (1997) The physics of debris flows. Reviews of Geophysics 35(3): 245-296.

Iverson RM and Denlinger RP (2001) Flow of variably fluidized granular masses across three-dimensional terrain. Coulomb mixture theory. Journal of Geophysical Research 106(B1): 537-552.

Iverson RM, Logan M, LaHusen RG and Berti M (2010) The perfect debris flow? Aggregated results from 28 large-scale experiments. Journal of Geophysical Research 115: F03005.

Jakob M and Hungr O (2005) Debris-flow Hazards and Related Phenomena. Springer Verlag, New York, NY, USA.
Konagai K, Tamura C, Rangelow P and Matsushima T (1992) Laser-aided tomography: a tool for visualization of changes in the fabric of granular assemblage. Structural Dynamics and Earthquake Engineering 9(3): 193-201.

Kozeny J (1927) Ueber kapillare Leitung des Wassers im Boden. Wien, Akadademie Wissenschaft 136(2a): 271 (in German).

Loudon AG (1952) The computation of permeability from simple soil tests. Géotechnique 3(4): 165-183.

Mainali A and Rajaratnam N (1994) Experimental study of debris flows. Journal of Hydraulic Engineering 120(1): 104-123.

Major JJ (1997) Depositional processes in large-scale debrisflow experiments. Journal of Geology 105(3): 345-365.

McArdell BW, Bartelt P and Kowalski J (2007) Field observations of basal forces and fluid pressure in a debris flow. Geophysical Research Letters 34: L07406.

Michalowski RL (1984) Flow of granular material through a plane hopper. Powder Technology 39(1): 29-40.

Montemagno CD and Gray WG (1995) Photoluminescent volumetric imaging: A technique for the exploration of multiphase flow and transport in porous media. Geophysical Research Letters 22(4): 425-428.

Okada Y and Ochiai H (2008) Flow characteristics of 2-phase granular mass flows from model flume tests. Engineering Geology 97(1-2): 1-14.

Papa M, Egashira S and Itoh T (2004) Critical conditions of bed sediment entrainment due to debris flow. Natural Hazards and Earth System Sciences 4(3): 469-474.

Parsons JD, Whipple KX and Simoni A (2001) Laboratory experiments of the grain-flow, fluid-mud transition in debris flows. Journal of Geology 109(4): 427-447.

Pierson TC (1980) Erosion and deposition by debris flows at Mt. Thomas, North Canterbury, New Zealand. Earth Surface Processes 5(3): 227-247.

Pitman EB and Le L (2005) A two-fluid model for avalanche and debris flows. Philosophical Transactions of the Royal Society A 363(1832): 1573-1601.

Pitman EB, Nichita CC, Patra AK, Bauer AC, Bursik M and Weber A (2003) A model of granular flows over an erodible surface. Discrete Continuum Dynamic Systems B 3(4): 589-599.

Rombi J, Pooley EJ and Bowman ET (2006) Factors influencing granular debris flow behaviour: an experimental investigation. In Proceedings of the 6th International Conference on Physical Modelling in Geotechnics ( $\mathrm{Ng}$ CWW, Wang YH and Zhang LM (eds)). Balkema, Rotterdam, the Netherlands, pp. 379-384.

Sanvitale N, Bowman ET and Genevois R (2011) Experimental measurements of velocity through granular-liquid flows. In Proceedings of the 5th International Conference on Debrisflow Hazards Mitigation: Mechanics, Prediction and Assessment (Genevois R, Hamilton DL and Prestininzi A (eds)). Casa Editrice Universita La Sapienza, Rome, Italy, pp. 375-384. 
Internal imaging of saturated granular free-surface flows

Sanvitale and Bowman
Savage SB (1979) Gravity flow of cohesionless granular materials in chutes and channels. Journal of Fluid Mechanics 92(1): 53-96.

Savage SB and Hutter K (1989) The motion of a finite mass of granular material down a rough incline Journal of Fluid Mechanics 199: 177-215.

Savage SB and Jeffrey DJ (1981) The stress tensor in a granular flow at high shear rates. Journal of Fluid Mechanics 110(1): 255-272.

Schaefer M, Bugnion L, Kern M and Bartelt P (2010) Position dependent velocity profiles in granular avalanches. Granular Matter 12(3): 327-336.

Slominski C, Niedostatkiewicz M and Tejchman J (2007) Application of particle image velocimetry (PIV) for deformation measurement during granular silo flow. Powder Technology 173(1): 1-18.

Sperry JM and Peirce JJ (1995) A model for estimating the hydraulic conductivity of granular material based on grain shape, grain size, and porosity. Ground Water 33(6): 892-898.

Stohr M, Roth K and Jahne B (2003) Measurement of 3D porescale flow in index-matched porous media. Experiments in Fluids 35(2): 159-166.

Suwa H (1988) Focusing mechanism of large boulders to a debris-flow front. Japanese Geomorphological Union Transactions 9(3): 151-178.
Takahashi T (1991) Debris Flow. IAHR Monograph. Balkema, Rotterdam, the Netherlands.

Takahashi T (2007) Debris Flow: Mechanics, Prediction and Countermeasures. Taylor \& Francis, Abingdon, UK.

Taylor DW (1948) Fundamentals of Soil Mechanics. Wiley, New York, NY, USA.

Terzaghi C (1925) Determination of the permeability of clay. Engineering News Records 95(21): 832-836.

Tognacca C and Minor HE (2000) Role of surface tension, fluid density and fluid viscosity on debris-flow dynamics. In Proceedings of the 2nd International Conference on Debrisflow Hazards Mitigation: Mechanics, Prediction and Assessment (Wieczorek G and Naeser ND (eds)). Balkema, Rotterdam, the Netherlands, pp. 229-235.

Wiederseiner S, Andreini N, Epely-Chauvin G and Ancey C (2011) Refractive-index and density matching in concentrated particle suspensions: a review. Experiments in Fluids 50(5): 1183-1206.

Zhou GD, Law RPH and Ng CWW (2009) The mechanisms of debris flow: a preliminary study. In Proceedings of the 17th International Conference on Soil Mechanics \& Geotechnical Engineering (Hamza M, Shahien M and El-Mossallamy Y (eds)). IOS Press, Amsterdam, the Netherlands, pp. 15701573 .

\section{WHAT DO YOU THINK?}

To discuss this paper, please email up to 500 words to the editor at journals@ice.org.uk. Your contribution will be forwarded to the author(s) for a reply and, if considered appropriate by the editorial panel, will be published as discussion in a future issue of the journal.

International Journal of Physical Modelling in Geotechnics relies entirely on contributions sent in by civil engineering professionals, academics and students. Papers should be 2000-5000 words long (briefing papers should be 1000 2000 words long), with adequate illustrations and references. You can submit your paper online via www.icevirtuallibrary.com/content/journals, where you will also find detailed author guidelines. 